\title{
Autoantibodies against C1q as a Diagnostic Measure of Lupus Nephritis: Systematic Review and Meta-analysis
}

Paul Eggleton $^{1 *}$, Obioha C. Ukoumunne ${ }^{2}$, Isabel Cottrell ${ }^{1}$, Asma Khan ${ }^{1}$, Sidra Maqsood ${ }^{1}$, Jemma Thornes ${ }^{1}$, Elizabeth Perry ${ }^{1}$ and David Isenberg ${ }^{3}$

${ }^{1}$ Institute of Biomedical and Clinical Sciences, University of Exeter Medical School, University of Exeter, Exeter, UK

${ }^{2}$ NIHR CLAHRC South West Peninsula (PenCLAHRC), University of Exeter Medical School, University of Exeter, Exeter, UK

${ }^{3}$ This address should read 'Centre for Rheumatology, Department of Medicine University College London, UK

"Corresponding author: Paul Eggleton, MPhil, PhD, University of Exeter Medical School, University of Exeter, Exeter EX1 2LU, UK, Tel: +44 (0)1392 722940; E-mail: p.eggleton@exeter.ac.uk

Received date: Mar 14, 2014, Accepted date: Apr 15, 2014, Published date: Apr 22, 2014

Copyright: @ 2014 Eggleton $\mathrm{P}$, et al. This is an open-access article distributed under the terms of the Creative Commons Attribution License, which permits unrestricted use, distribution, and reproduction in any medium, provided the original author and source are credited.

\begin{abstract}
Objectives: To evaluate the diagnostic accuracy of $\mathrm{C} 1 \mathrm{q}$ autoantibodies in identifying lupus nephritis (LN) in patients with systemic lupus erythematosus (SLE).

Data sources and methods: Citation indexes were searched and 370 articles published from 1977 to 2013 were evaluated. The 31 selected studies included in the meta-analysis were cross-sectional in design. Among the 31 studies, 28 compared anti-C1q antibodies in 2769 SLE patients with $(n=1442)$ and without a history of LN ( $n=1327)$. Nine studies examined anti-C1q in 517 SLE patients with active $(n=249)$ and inactive LN ( $n=268)$. Hierarchical summary receiver operating characteristic (HSROC) random effects models were fitted to pool estimates of accuracy across the studies.
\end{abstract}

Results: Anti-C1q antibodies discriminated between patients with and without a history of LN, with a median specificity of $73.5 \%$. The HSROC model estimated the corresponding sensitivity to be $70.4 \%$. A hypothetical patient with a $55 \%$ prior probability of having a history of $L N$ as opposed to no history (the median prevalence across 28 eligible studies) would have a post-test probability of $76.4 \%$ following a positive test result (positive predictive value) or $33.0 \%$ following a negative test result (negative predictive value). For discriminating active from inactive $\mathrm{LN}$ the median specificity of anti-C1q antibodies was $80 \%$, with a corresponding estimated sensitivity value $75.7 \%$ based on the HSROC model. A hypothetical patient with a $56 \%$ prior probability of active as opposed to inactive LN (the median prevalence across the 9 eligible studies) would have a post-test probability of $82.8 \%$ following a positive test result or $27.9 \%$ following a negative test result.

Conclusions: Although $\mathrm{C} 1 \mathrm{q}$ antibodies are associated with lupus nephritis the post-test probabilities are not sufficiently convincing to provide reasonable certainty of the presence or absence of history of disease/active disease.

Keywords: Autoantibody; Biopsy; Diagnosis; Enzyme-linked immunosorbent assay (ELISA); Hierarchical summary receiver operating characteristic (HSROC); First component of complement (C1q); Systemic lupus erythematosus (SLE)

\section{Introduction}

The first component of complement - $\mathrm{C} 1$ is comprised of three subcomponents, $\mathrm{C} 1 \mathrm{q}, \mathrm{C} 1 \mathrm{~s}$ and $\mathrm{C} 1 \mathrm{r}$. The $\mathrm{C} 1$ complex plays a pivotal role in the activation of the classical pathway of complement. Classical complement activation has both inflammatory and anti-inflammatory functions. Intensive research in the 1970s afforded detailed information on the structure and function of C1q [1]. The C1q molecule is a $460 \mathrm{kDa}$ glycoprotein with an exquisite tulip-like structure, consisting of six globular heads each made up from three polypeptide chains - A, B and C. Each head is attached to a central fibril region by a triple helical collagen like tail. The $\mathrm{C} 1 \mathrm{q}$ component of $\mathrm{C} 1$ is synthesized in monocyte/macrophages and once secreted, can bind to aggregated antibody [2] primarily on microorganisms. This event triggers the activation of the classical complement pathway that in turn amplifies the innate and adaptive immune responses against infectious agents. $\mathrm{Clq}$ is a multi-functional protein [3], and binds to immune complexes deposited on tissues, including the kidney [4], and aids in their solubilization and removal [5]. C1q also plays a role in apoptotic cell debris removal [6]. Forty years ago, the possibility of antibodies against C1q in SLE patients was raised [7]. It was later proposed that binding of $\mathrm{Clq}$ to immune complexes led to conformational changes in the C1q structure exposing neoepitopes [8] that may invoke an immune response. Evidence for such a response, was demonstrated by Uwatoko et al., who observed that IgG from SLE patient sera cross-reacted with C1q [9]. In later studies, we and others, suggested that post-translational modifications of $\mathrm{C} 1 \mathrm{q}$ upon exposure to free radicals could generate antigenic neoepitopes [10-13] which could act as a 'trigger', leading to the breakdown of immune tolerance to $\mathrm{C} 1 \mathrm{q}$; this effect together with 'epitope spreading' could then provoke the generation of antibodies to both post-translationally modified and unmodified forms of C1q (Figure 1). The binding of anti-C1q antibodies and other proteins to $\mathrm{Clq}$ is potentially of concern as it may impede the ability of $\mathrm{Clq}$ to carry out its normal 
Citation: Eggleton P, Ukoumunne OC, Cottrell I, Khan A, Maqsood S, et al. (2014) Autoantibodies against C1q as a Diagnostic Measure of Lupus Nephritis: Systematic Review and Meta-analysis. J Clin Cell Immunol 5: 210. doi:10.4172/2155-9899.1000210

Page 2 of 14

anti-inflammatory functions such as, immune complex clearance and removal of apoptotic debris $[14,15]$.

SLE is a multisystem autoimmune disorder with a broad spectrum of clinical presentations. Due to the heterogeneity of the disease and the absence of a single diagnostic test the diagnosis of SLE remains challenging [16]. Current clinical practice requires integration of patient's symptoms, physical examination and diagnostic tests. Lupus nephritis (LN), a marker of adverse outcome in SLE is common developing in approximately $30-50 \%$ of patients overall often in the first year after diagnosis [17]. The cumulative relapse rate for $\mathrm{LN}$ is in the region of $25-40 \%$ at 5 years [18] with patients experiencing multiple episodes of active nephritis at increased risk of progressing to end stage renal disease [19]. Early recognition of LN is imperative to facilitate treatment however it is clinically and histologically heterogeneous. Diagnosis and monitoring of LN remains a considerable clinical challenge $[20,21]$.

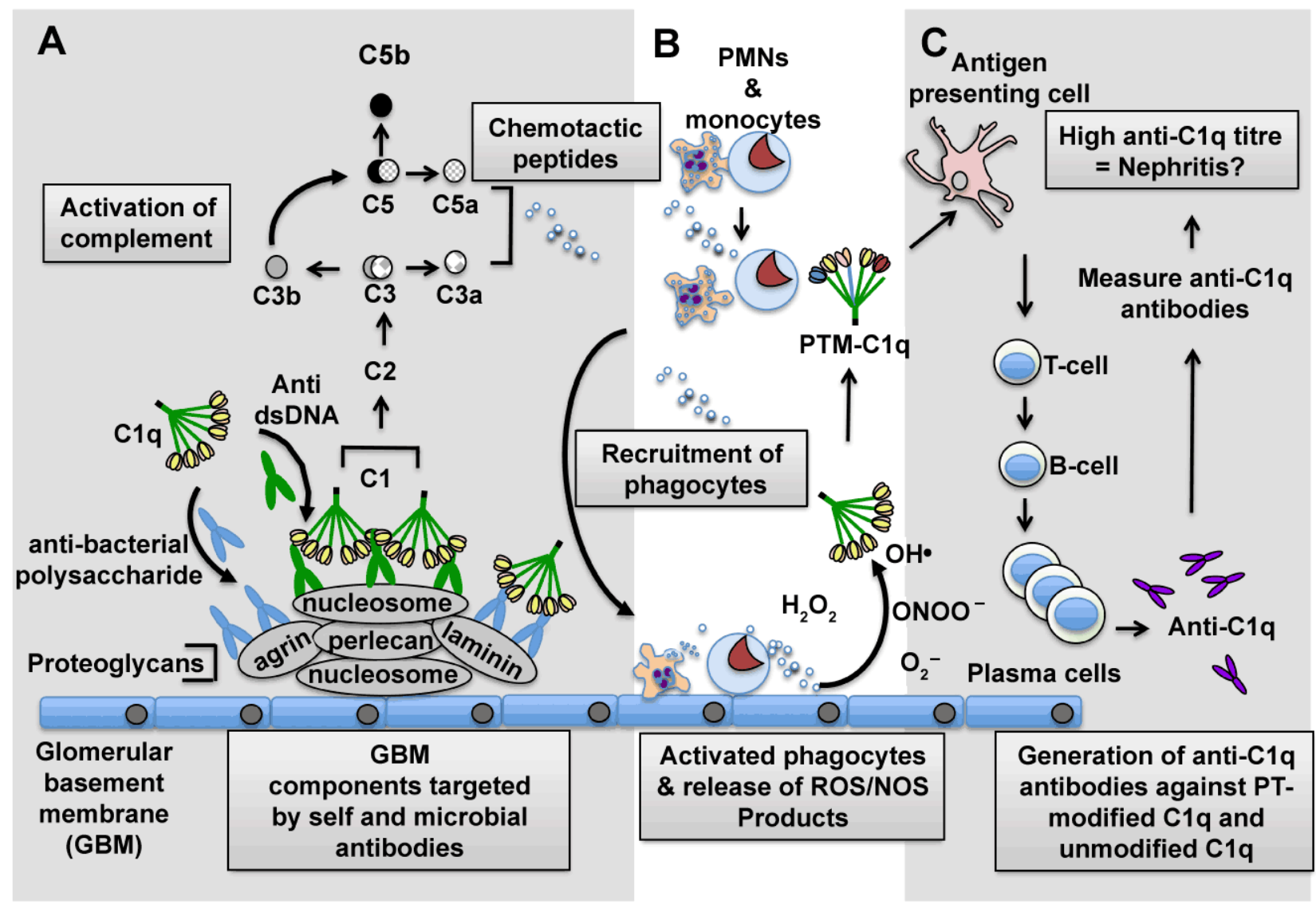

Figure 1: Postulated sequence of events in the generation of anti-C1q antibodies that may act as diagnostic biomarkers of glomerulonephritis. Nucleosome blebs from apoptotic cells can deposit on the glomerular basement membrane (GBM) in SLE patients with LN and associate with a number of proteoglycan molecules. (A) During infection and/or inflammation anti-bacterial polysaccharide or anti-dsDNA antibodies bind to host proteoglycans and nucleosomes, respectively. This leads to the deposition of $\mathrm{C} 1\left(\mathrm{C} 1 \mathrm{q} / \mathrm{C}_{1} \mathrm{r}_{2} / \mathrm{C}_{1} \mathrm{~s}_{2}\right)$ on the $\mathrm{GBM}$ and subsequent complement activation. (B) The release of chemotactic peptides C5a and C3a triggers the recruitment of phagocytes to the GBM in close proximity to C1q. The activation of the phagocytes leads to the release of free radicals that can post-translationally modify (PTM) C1q. (C) The PTM-C1q can be taken up by antigen presenting cells, and the modified peptides presented to T-cells. The autoreactive T-cells in turn can trigger B-cell activation and ultimately the production of anti-C1q-producing plasma cells. The concentration of anti-C1q antibodies produced in the blood can then detected by various immunoassays, including ELISA and used to assess whether a patient has or has not got nephritis.

Many autoantibodies are prevalent in unselected SLE patients. Up to $70 \%$ of patients have autoantibodies against single stranded-DNA (ssDNA), $40-70 \%$ of patients have double-stranded DNA (dsDNA) autoantibodies and around 95\% of patients have anti-nuclear (ANA) antibodies [22]. ANA and anti-ssDNA have been useful markers of SLE disease in general, but have low specificity and are found in many other types of musculoskeletal disorders and in infection diseases [23].
In the 1990s, a number of studies proposed that autoantibodies against C1q in SLE patients might be pathogenic and be associated with nephritis severity $[24,25]$. This led to a series of cross-sectional studies in both Europe and the USA aimed at determining if a correlation existed between the presence and concentration of anti-C1q antibodies in SLE patient sera and the severity of their nephritis [26-32]. In one early study, Siegert et al. concluded that anti-C1q autoantibodies do 
Citation: Eggleton P, Ukoumunne OC, Cottrell I, Khan A, Maqsood S, et al. (2014) Autoantibodies against C1q as a Diagnostic Measure of Lupus Nephritis: Systematic Review and Meta-analysis. J Clin Cell Immunol 5: 210. doi:10.4172/2155-9899.1000210

Page 3 of 14

not correlate with general SLE disease activity, but found a positive correlation between anti-C1q antibody titers and nephritis [30]. Since then numerous other studies have assessed the usefulness of measuring anti-C1q as a non-invasive means of detecting and monitoring LN in SLE patients. The majority of these studies agree that measurement of anti-C1q antibodies is a useful additional serological marker for monitoring LN. However, due to the low frequency of SLE in the general population, many of the single and multicenter studies have recruited relatively small numbers of patients between 15 and 250 individuals. Several studies have concluded antiC1q is not a useful marker for LN [33], others 'slightly' useful [34] and others very useful for predicting renal disease [35]. This has resulted in a lack of confidence in measuring anti-C1q in a clinical setting and to date it is not used routinely as a diagnostic test for LN.

Given the importance of the potential association between anti-C1q antibodies and LN, we systematically reviewed and performed a metaanalysis of the accuracy of anti-C1q amongst SLE patients to distinguish a) between those with and without history of LN, and b) between those with active and inactive LN.

\section{Studies and Methods}

\section{Identification, selection and quality assessment of studies}

We searched the terms 'nephritis', 'lupus' and 'C1q' in the 'any field' bar of EndnoteX4.0.2 using several online search libraries - PubMed (290 citations), Web of Science -TS (197 citations), National Library of Medicine-USA ( 2 citations) of which 176 references were duplicates (Figure 2). In addition, Annual Reviews, Science Direct, Medline (EBSCO), Biomed Central, BMJ Journals, Cambridge Journals, EBSCO EJS, Oxford Journals, Medline (Ovid), NHS Evidence, AMED (EBSCO) and the Exeter Health Library online journal collection were searched to ensure all relevant articles were retrieved. Four authors (IC, AK, SM and JT) in pairs independently assessed the studies for the accuracy of $\mathrm{Clq}$ autoantibodies to diagnose $\mathrm{LN}$ as measured by an enzyme-linked immunosorbant assay (ELISA). We also examined the references of all the publications we identified to ensure we had not omitted publications other authors had identified. When data were difficult to extract from the papers, the corresponding authors were contacted and given the opportunity to respond.

Studies were chosen that had employed a lab-made or commercial ELISA to screen for anti-C1q autoantibodies in 12 or more patients per study.

QUADAS-2 (quality assessment of diagnostic accuracy studies) was used to evaluate the risk of bias and applicability of all the studies included in the meta-analysis [36] (http://www.bris.ac.uk/quadas/ quadas-2/). The tool assesses the quality of patient selection, the appropriateness of the index test employed (anti-C1q ELISA), the quality of the reference standard as the criterion for disease (lupus nephritis) and the flow and timing of the study (time of sample collection and analysis).

\section{Statistical analysis}

The study-specific results were extracted in the form of $2 \times 2$ contingency tables (relating the test result to disease status) for analysis. Sensitivity and specificity estimates are reported for each study using coupled forest plots. Sensitivity/specificity values for the studies are also shown on summary receiver operating characteristic (sROC) plots. Hierarchical summary receiver operating characteristic
(HSROC) random effects meta-analysis models [37] were fitted to pool estimates of accuracy of anti-C1q for discriminating between patients with and without history of LN and between patients with active $\mathrm{LN}$ and with inactive LN. The HSROC model recognizes the statistical heterogeneity across studies and the trade-off between sensitivity and specificity that results from the use of different thresholds to define a positive result on the anti-C1q test. The fitted model defines a summary ROC curve with a specific position (accuracy) and shape. Here we report the sensitivity value on the fitted summary ROC curve that corresponds to the median of the specificity values across the studies. Positive and negative likelihood ratios are reported and in turn used to calculate post-test probabilities of nephritis following a positive or negative anti-C1q test result for patients with a pre-test probability of disease (or prevalence) equal to the median percentage with nephritis across the studies. The post-test probability of nephritis following a positive test result is the positive predictive value and the post-test probability following a negative test result is the complement of the negative predictive value.

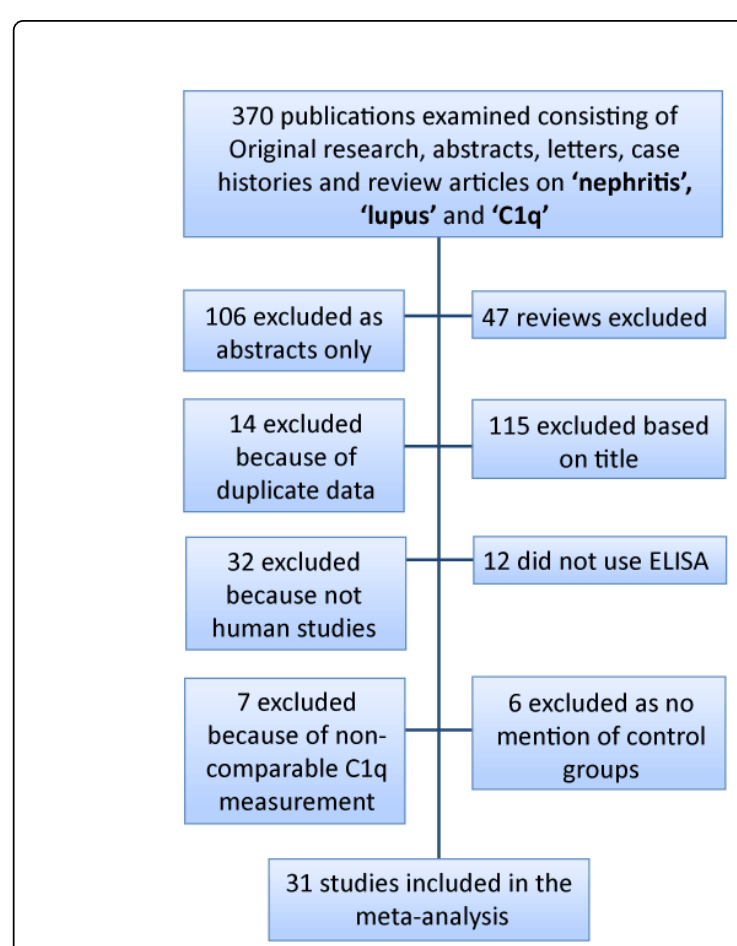

Figure 2: Flow chart for the systematic selection of studies for inclusion in the meta-analysis.

The HSROC models were fitted using a Bayesian framework in WinBUGS software (http://www.mrc-bsu.cam.ac.uk/bugs/winbugs). Rutter and Gatsonis [37] have described the model in detail. Uniform priors were specified for the accuracy, threshold (representing the cutpoint on anti-C1q to indicate a positive result) and shape (representing the degree of asymmetry of the summary ROC curve) model parameters and inverse-gamma priors were specified for the parameters that represent between-study variance for accuracy and threshold. Starting values were set to zero for the accuracy and threshold parameters and to 0.2267 for the shape parameter; to 5 for the between-study variance components for accuracy and threshold; and to zero for the study-specific random effects for accuracy and 
Citation: Eggleton P, Ukoumunne OC, Cottrell I, Khan A, Maqsood S, et al. (2014) Autoantibodies against C1q as a Diagnostic Measure of Lupus Nephritis: Systematic Review and Meta-analysis. J Clin Cell Immunol 5: 210. doi:10.4172/2155-9899.1000210

Page 4 of 14

shape. For estimation, a burn-in of 10,000 iterations was used followed by a further 100,000 iterations for the main run to monitor the posterior distributions. Revman 5.2 software was used to produce the couple forest plots and the summary ROC plots [38].

\section{Results}

\section{Demographic characteristics of the patients}

The meta-analysis included 31 studies in total (Table 1). Twenty eight studies with a total of 2769 SLE patients provided data to compare anti-C1q test result between those with $(\mathrm{n}=1442)$ and without $(\mathrm{n}=1327)$ a history of nephritis. Nine studies with a total of 517 SLE patients provided data to compare anti-C1q test result between those with active $(n=249)$ and in active $L N(n=268)$ at the time of blood sampling.

The ethnicities of the studies were diverse and included studies from Europe (17/31 studies; 55\%), Asia (9 studies; 29\%), North and South America (5 studies; 16\%). Twenty nine of the studies assessed anti-C1q status and LN in adults and some teenagers (age $\geq 15$ years,

\begin{tabular}{|c|c|c|c|c|c|c|}
\hline Reference & $\begin{array}{c}\text { Country \& study } \\
\text { date }\end{array}$ & $\begin{array}{l}\text { Patient Number } \\
\text { (samples) }\end{array}$ & $\%$ female & $\begin{array}{l}\text { Median/Mean Pooled } \\
\text { Age (range or Mean } \pm \\
\text { SD) }\end{array}$ & $\begin{array}{c}\text { Disease } \\
\text { duration Years } \\
\text { Median (range) } \\
\text { or mean } \pm \text { SD) }\end{array}$ & $\begin{array}{l}\text { Disease criteria \& activity } \\
\text { Index }\end{array}$ \\
\hline \multicolumn{7}{|l|}{ European studies } \\
\hline Siegert et al. [30] & $\begin{array}{l}\text { Netherlands } \\
\text { (1991) }\end{array}$ & 88 & $91 \%$ & $37(15-73)$ & NR & ACR criteria/SLEDAI \\
\hline Siegert et al. [31] & $\begin{array}{l}\text { Netherlands } \\
\text { (1993) }\end{array}$ & 68 & $96 \%$ & $38(14-75)$ & $6(0.8-24)$ & ACR criteria/ SLEDAI \\
\hline \multirow[t]{2}{*}{ Coremans et al. [27] } & $\begin{array}{l}\text { Netherlands } \\
\text { (1995) }\end{array}$ & 33 & $85 \%$ & * $28.9 \pm 10.2$ & ${ }^{*}(3.7 \pm 3.7)$ & ACR criteria \\
\hline & & & & $† 34.3 \pm 10.1$ & $\dagger(8.9 \pm 6.7)$ & \\
\hline${ }^{* \star}$ Ravelli et al. [57] & $\begin{array}{l}\text { Italy } \\
(1997)\end{array}$ & 29 & $90 \%$ & $14.1(7.5-19.6)$ & $(0.1-14.6)$ & ACR criteria/ SLEDAI/SLAM \\
\hline Norsworthy et al. [29] & $\begin{array}{l}\text { UK } \\
(1999)\end{array}$ & 195 & NR & NR & $0.25-25$ & BILAG \\
\hline Trendelenberg et al. [58] & $\begin{array}{l}\text { Switzerland } \\
\text { (1999) }\end{array}$ & 48 & NR & NR & NR & ACR criteria \\
\hline Loizou et al. [59] & $\begin{array}{l}\text { UK } \\
(2000)\end{array}$ & 56 & $95 \%$ & $\begin{array}{l}\text { * } 31(17-61) \\
\S 43(15-74)\end{array}$ & $20-71$ & ACR criteria \\
\hline \multirow[t]{2}{*}{ Moroni et al. [60] } & $\begin{array}{l}\text { Italy } \\
(2001)\end{array}$ & $48(61)$ & $92 \%$ & * $34(23-43)$ & 10.1 & ACR criteria/SLEDAI \\
\hline & & & & $\S 38(29-49)$ & 11.3 & \\
\hline Oelzner et al. [61] & $\begin{array}{l}\text { Germany } \\
(2003)\end{array}$ & 79 & $89 \%$ & $41.7 \pm 13.8$ & $0.25-30$ & ACR criteria/SLEDAI \\
\hline Marto et al. [62] & $\begin{array}{l}\text { UK } \\
(2005)\end{array}$ & 151 & $93 \%$ & $39(15-74)$ & NR & ACR criteria \\
\hline Sinico et al. [63] & $\begin{array}{l}\text { Italy } \\
(2005)\end{array}$ & 61 & NR & NR & NR & ACR criteria/ECLAM \\
\hline
\end{tabular}

range 15-77), four studies focused on pediatric patients (mean age 13.9 years). Patients were recruited into the various studies with a diagnosis of SLE ranging from 2 months to 49 years (Table 1). The percentage of participants that was female exceeded $80 \%$ in 22 of the 24 studies that reported these data. The majority of the studies diagnosed SLE (30/31) using one of the American College of Rheumatology (ACR) classifications [39,40]. A large proportion of studies (23 of 31) also used a disease activity index to assess renal activity (Table 2), with the SLEDAI and SLEDAI-2K being the most frequently used (21 studies). The studies in which only ACR criteria were used tended to be the earlier studies conducted between 1994 and 2000. Active and inactive LN was assessed using a variety of well-established clinical parameters, including excessive proteinuria, increase in creatinine and/or the presence of red blood cells or cellular casts in the urine. As shown in Table 2, there was no unified consensus how active nephritis was monitored. The majority of the studies (28/31) used a renal biopsy as the reference standard to diagnose active LN or historical evidence of past episodes of nephritis, only 3 studies did not report confirmatory biopsy for evidence of nephritis. 
Citation: Eggleton P, Ukoumunne OC, Cottrell I, Khan A, Maqsood S, et al. (2014) Autoantibodies against C1q as a Diagnostic Measure of Lupus Nephritis: Systematic Review and Meta-analysis. J Clin Cell Immunol 5: 210. doi:10.4172/2155-9899.1000210

Page 5 of 14

\begin{tabular}{|c|c|c|c|c|c|c|}
\hline Jaekell et al. [64] & $\begin{array}{l}\text { Germany } \\
(2006)\end{array}$ & 100 & $91 \%$ & $41.7 \pm 13.7$ & NR & ACR criteria/ECLAM \\
\hline **Kozyro et al. [65] & $\begin{array}{l}\text { Switzerland } \\
(2006)\end{array}$ & 12 & $50 \%$ & $15(10-17)$ & NR & ACR criteria/SLEDAI \\
\hline Trendelenberg et al. [66] & $\begin{array}{l}\text { Switzerland } \\
(2006)\end{array}$ & 72 & NR & NR & NR & ACR criteria \\
\hline Braun et al. [67] & $\begin{array}{l}\text { Germany } \\
(2007)\end{array}$ & 78 & $88 \%$ & $37.6 \pm 12.3$ & $0.08-33.0$ & ACR criteria/SLEDAI \\
\hline Meyer et al. [68] & $\begin{array}{l}\text { France } \\
\text { (2009) }\end{array}$ & 70 & $91 \%$ & $\begin{array}{l}\S 30(19-58) \\
\S 28(17-48) \\
35(20-76)\end{array}$ & $\begin{array}{l}0.25-36 \\
0.1-14.1 \\
1.1-49.0\end{array}$ & ACR criteria/SLEDAI \\
\hline $\begin{array}{l}\text { Smykal-Jankowiak et al. } \\
\text { [69] }\end{array}$ & $\begin{array}{l}\text { Poland } \\
\text { (2011) }\end{array}$ & 48 & $100 \%$ & * 33.5 & 5.35 & ACR criteria/SLEDAI-2K \\
\hline \multicolumn{7}{|l|}{ Asian studies } \\
\hline Fang et al. [70] & $\begin{array}{l}\text { China } \\
(2009)\end{array}$ & 180 & $84 \%$ & $\begin{array}{l}\text { * } 33 \pm 11.34 \\
\text { ๆ } 31.37 \pm 11.70\end{array}$ & NR & ACR criteria/SLEDAI \\
\hline Tan et al. [45] & $\begin{array}{l}\text { China } \\
\text { (2009) }\end{array}$ & 113 & NR & NR & NR & ACR criteria/SLEDAI \\
\hline Cai et al. [71] & $\begin{array}{l}\text { China } \\
(2010)\end{array}$ & 73 & $89 \%$ & $\ddagger 31.0 \pm 13.9$ & $\ddagger(2.3 \pm 1.6)$ & ACR criteria/SLEDAI \\
\hline Mok et al. [72] & $\begin{array}{l}\text { China } \\
(2010)\end{array}$ & 245 & $95 \%$ & $40.6 \pm 12.2$ & $8.7 \pm 7.1$ & $\begin{array}{l}\text { ACR } \\
\text { SLEDAI }\end{array}$ \\
\hline Pradhan et al. [73] & $\begin{array}{l}\text { India } \\
(2010)\end{array}$ & 80 & NR & NR & NR & ACR criteria/SLEDAI \\
\hline Katsumata et al. [33] & $\begin{array}{l}\text { Japan } \\
\text { (2011) }\end{array}$ & 126 & $98 \%$ & $37(17-77)$ & $N R$ & ACR criteria/SLEDAI-2K \\
\hline **Wu et al. [74] & $\begin{array}{l}\text { China } \\
(2011)\end{array}$ & 90 & $87 \%$ & $9.8(3-15)$ & NR & ACR criteria/SLEDAI-2K \\
\hline Zhang et al. [75] & $\begin{array}{l}\text { China } \\
(2011)\end{array}$ & 90 & $98 \%$ & $37.08 \pm 11.89$ & 4.08 & ACR criteria/SLEDAI \\
\hline & & & & * $34.67 \pm 11.21$ & 4.74 & \\
\hline & & & & ๆ $39.95 \pm 12.12$ & 3.28 & \\
\hline Pradhan et al. [76] & $\begin{array}{l}\text { India } \\
(2012)\end{array}$ & 60 & $92 \%$ & $29.7(17-49)$ & $3.6 \pm 1.4$ & ACR criteria/SLEDAI \\
\hline \multicolumn{7}{|c|}{ North/South American Studies } \\
\hline Bernstein et al. [26] & $\begin{array}{l}\text { USA } \\
(1994)\end{array}$ & 60 & NR & NR & NR & ACR criteria \\
\hline Haseley et al. [28] & $\begin{array}{l}\text { USA } \\
(1997)\end{array}$ & 240 & $92 \%$ & $41 \pm 9.0$ & $(11 \pm 9.0)$ & ACR criteria \\
\hline Moura et al. [77] & $\begin{array}{l}\text { Brazil } \\
(2009)\end{array}$ & 81 & $99 \%$ & $34 \pm 11$ & $4(0.3-32)$ & ACR criteria/SLEDAI \\
\hline De Moura et al. [78] & Brazil & 62 & $85 \%$ & $* 27.0 \pm 5$ & NR & ACR criteria/SLEDAI \\
\hline
\end{tabular}


Citation: Eggleton P, Ukoumunne OC, Cottrell I, Khan A, Maqsood S, et al. (2014) Autoantibodies against C1q as a Diagnostic Measure of Lupus Nephritis: Systematic Review and Meta-analysis. J Clin Cell Immunol 5: 210. doi:10.4172/2155-9899.1000210

Page 6 of 14

\begin{tabular}{|c|c|c|c|c|c|c|}
\hline & (2011) & & & & & \\
\hline & & & & $\dagger 27.5 \pm 6.3$ & & \\
\hline & & & & ๆ $28.0 \pm 8.0$ & & \\
\hline **Jesus et al. [79] & $\begin{array}{l}\text { Brazil } \\
\text { (2012) }\end{array}$ & 67 & $78 \%$ & $14.6 \pm 3.86$ & $(6.4 \pm 3.52)$ & ACR criteria/SLEDAI-2K \\
\hline
\end{tabular}

Table 1: Summaries of demographic information of the 31 studies included in the meta-analysis.

\begin{tabular}{|c|c|c|c|c|c|}
\hline \multirow[t]{2}{*}{ Reference } & \multicolumn{3}{|c|}{ Renal Disease Reference standards } & \multirow{2}{*}{$\begin{array}{c}\text { Immunoassay } \\
\text { used }\end{array}$} & \multirow[t]{2}{*}{ Cut-off for +ve result } \\
\hline & Biopsy WHO GN types I-VI & $\begin{array}{l}\text { Proteinuria(P)/ Creatinine } \\
\text { (C) }\end{array}$ & RBC count/field & & \\
\hline Siegert et al. [30] & 13/88 biopsy & $\begin{array}{l}\mathrm{P}>0.5 \mathrm{~g} / 24 \mathrm{~h} \\
\text { Increased } \mathrm{C}\end{array}$ & $>10$ & Lab -made & $>137 \mathrm{U} / \mathrm{ml}$ \\
\hline Siegert et al. [31] & 25/68 biopsy & $P>0.5 \mathrm{~g} / 24 \mathrm{~h}$ & RBCs in urine & Lab-made & $>90 \mathrm{U} / \mathrm{ml}$ \\
\hline Coremans et al. [27] & 17/33 biopsy & $\mathrm{P}>0.5 \mathrm{~g} / 24 \mathrm{~h}$ & $>5$ & Lab-made & $>90 \mathrm{U} / \mathrm{ml}$ \\
\hline ** Ravelli et al. [57] & $7 / 29$ biopsy & $\begin{array}{l}\mathrm{P}>0.5 \mathrm{~g} / 24 \mathrm{~h} \\
\text { Increased } \mathrm{C}\end{array}$ & $>10$ & Lab-made & $\begin{array}{l}>\text { mean } 95 \% \text { OD above } 59 \mathrm{HC} \\
\text { controls }\end{array}$ \\
\hline Norsworthy et al. [29] & 37/199 biopsy & $P>15 \mathrm{mg} / 24 \mathrm{~h}$ & $>10$ & Lab-made & $>20 \mathrm{U}+5 \mathrm{SD}$ above controls \\
\hline $\begin{array}{l}\text { Trendelenberg et al. } \\
\text { [58] }\end{array}$ & 14/48 biopsy & Abnormal values of $P$ & $>20$ & Lab-made & $>80 \mathrm{U} / \mathrm{ml}$ \\
\hline Loizou et al. [59] & 31/56 biopsy & Abnormal P & NR & Lab-made & $>20 \mathrm{U}+5 \mathrm{SD}$ above controls \\
\hline Moroni et al. [60] & biopsy & $P>0.5 \mathrm{~g} / 24 \mathrm{~h}$ & $>5$ & Lab-made & $>80 \mathrm{U} / \mathrm{ml}$ \\
\hline Oelzner et al. [61] & 27/79 biopsy & $P \geq 0.5 \mathrm{~g} / 24 \mathrm{~h}$ & NR & IMTEC & $\geq 30 \mathrm{U} / \mathrm{ml}$ \\
\hline Marto et al. [62] & 77/151 biopsy & NR & NR & Diagenics & $>18 \mathrm{U} / \mathrm{ml}$ \\
\hline Sinico et al. [63] & 40/61 biopsy & $\mathrm{P}>2.0 \mathrm{~g} / 24 \mathrm{~h}$ & NR & Lab-made & $>55 \mathrm{U} / \mathrm{ml}$ \\
\hline Jaekell et al. [64] & Some biopsy & $\begin{array}{l}P \geq 0.5 \mathrm{~g} / 24 \mathrm{~h} \\
\text { Increased } \mathrm{C}\end{array}$ & NR & Orgentec & $>10 \mathrm{U} / \mathrm{ml}$ \\
\hline **Kozyro et al. [65] & 12/112 biopsy & $P>1 \mathrm{~g} / \mathrm{L}$ & $>20$ & Bühlmann & $>15 \mathrm{U} / \mathrm{ml}$ \\
\hline $\begin{array}{l}\text { Trendelenberg et al. } \\
\text { [66] }\end{array}$ & 40/72 biopsy & NR & $>20$ & Bühlmann & $>40 \mathrm{U} / \mathrm{ml}$ \\
\hline Braun et al. [67] & 47/78 biopsy & NR & & INOVA & $>20 \mathrm{U} / \mathrm{ml}$ \\
\hline Meyer et al. [68] & 55/70 biopsy & $\begin{array}{l}\mathrm{P}>0.5 \mathrm{~g} / \mathrm{dL} / 24 \mathrm{~h} \\
\text { Increased } \mathrm{C}\end{array}$ & Increased RBCs & Bühlmann & $>32 \mathrm{U} / \mathrm{ml}$ \\
\hline $\begin{array}{l}\text { Smykal-Jankowiak et } \\
\text { al. [69] }\end{array}$ & 37/48 Biopsy & $\begin{array}{l}P \geq 0.5 \mathrm{~g} / 24 \mathrm{~h} \\
\text { serum } C\end{array}$ & Increased RBCs & Bühlmann & $>32 \mathrm{U} / \mathrm{ml}$ \\
\hline Fang et al. [70] & Biopsy & $\begin{array}{l}\mathrm{P}>0.3 \mathrm{~g} / 24 \mathrm{~h} \\
\text { Increased } \mathrm{C}\end{array}$ & $\geq 5$ & Lab-made & $\begin{array}{l}>\text { mean } \mathrm{OD}+2 \mathrm{SD} \text { above } 63 \\
\text { controls }\end{array}$ \\
\hline Tan et al. [45] & Biopsy & NR & NR & Lab-made & $\begin{array}{l}>\text { mean OD }+2 \text { SD above } 100 \\
\text { controls }\end{array}$ \\
\hline Cai et al. [71] & Biopsy & $P \geq 0.5 \mathrm{~g} / 24 \mathrm{~h}$ & Increased RBCs & IMTEC & $>20 \mathrm{U} / \mathrm{ml}$ \\
\hline
\end{tabular}


Citation: Eggleton P, Ukoumunne OC, Cottrell I, Khan A, Maqsood S, et al. (2014) Autoantibodies against C1q as a Diagnostic Measure of Lupus Nephritis: Systematic Review and Meta-analysis. J Clin Cell Immunol 5: 210. doi:10.4172/2155-9899.1000210

Page 7 of 14

\begin{tabular}{|c|c|c|c|c|c|}
\hline Mok et al. [72] & NR & NR & NR & Euroimmun & NR \\
\hline Pradhan et al. [73] & Biopsy & NR & NR & Binding Site & $>8 \mathrm{U} / \mathrm{ml}$ \\
\hline Katsumata et al. [33] & 20/126 Biopsy & $P \geq 0.5 \mathrm{~g} / 24 \mathrm{~h}$ & NR & Bühlmann & $>40 \mathrm{U} / \mathrm{ml}$ \\
\hline **Wu et al. [74] & 28/90 Biopsy & $\begin{array}{l}\mathrm{P} \geq 50 \mathrm{mg} / \mathrm{Kg} / 24 \mathrm{~h} \\
\text { Increased C }\end{array}$ & NR & Lab-made & $\begin{array}{l}\text { >mean OD + } 1 \text { SD (40 U/ml) } \\
\text { above controls }\end{array}$ \\
\hline Zhang et al. [75] & 5/49 Biopsy & $P \geq 0.5 \mathrm{~g} / 24 \mathrm{~h}$ & Increased RBCs & Euroimmun & $\geq 20 \mathrm{U} / \mathrm{ml}$ \\
\hline Pradhan et al. [76] & 45/60 Biopsy & NR & NR & Autostat II C1q-CIC & $\geq 50 \mu \mathrm{g} / \mathrm{ml}$ anti-C1q \\
\hline Bernstein et al. [26] & 8/60 Biopsy & $\begin{array}{l}P \geq 0.5 \mathrm{~g} / 24 \mathrm{~h} \\
\text { Increased C }\end{array}$ & NR & Lab-made & $\begin{array}{l}\text { >mean } \mathrm{OD}+2 \mathrm{SD} \text { above } 30 \\
\text { inactive SLE controls }\end{array}$ \\
\hline Haseley et al. [28] & 75/240 Biopsy & $\begin{array}{l}P \geq 0.5 \mathrm{~g} / 24 \mathrm{~h} \\
\text { Increased } \mathrm{C}\end{array}$ & $>10$ & Lab-made & $\begin{array}{l}>\text { mean OD }+5 \text { SD above } 30 \\
\text { controls }\end{array}$ \\
\hline Moura et al. [77] & No & $\begin{array}{l}P \geq 0.5 \mathrm{~g} / 24 \mathrm{~h} \\
\text { Increased } C\end{array}$ & NR & INOVA & $>20 \mathrm{U} / \mathrm{ml}$ \\
\hline De Moura et al. [78] & 15/62 Biopsy & $\begin{array}{l}P \geq 0.5 \mathrm{~g} / 24 \mathrm{~h} \\
\text { serum } \mathrm{C}\end{array}$ & NR & Diagenics & $\geq 20 \mathrm{U} / \mathrm{L}$ \\
\hline **Jesus et al. [79] & No & $\begin{array}{l}P \geq 0.5 \mathrm{~g} / 24 \mathrm{~h} \\
\text { Increased } \mathrm{C}\end{array}$ & $>10$ & QUATA Lite & $>20 \mathrm{U} / \mathrm{ml}$ \\
\hline \multicolumn{6}{|l|}{ ** Pediatric study } \\
\hline
\end{tabular}

Table 2: Clinical assessment of nephritis and detection of anti-C1q antibodies in 31 studies.

\section{Detection and measurement of anti-C1q antibodies by ELISA}

The studies used in this analysis all utilized at least one or more ELISA-based immunoassays. Both lab-made and commercial anti-C1q ELISA's are used by various labs worldwide, and the decision to use one type rather than another may be based on economic reasons rather than assay precision (Table 2). Many of studies assessed both the presence or absence of anti-C1q and the titer of $\mathrm{Clq}$ antibodies in their disease cohorts. In this current investigation, we selected studies that used ELISA-based methods so that general comparisons could be made between studies.

One compounding observation that arose from this analysis was the differences in the selection of a cut-off value for anti-C1q antibody positivity (Table 2). Each study set its own criterion for 'lab-made' assays. Studies employing commercial assays in some instances changed the cut-off values as recommended by the manufacturers.

\section{Quality assessment}

The quality of the individual studies is reported in Figure 3 for the different criteria on the QUADAS-2 assessment tool in a format recommended by the QUADAS-2 design team. The majority of studies were cross-sectional in nature, recruiting unselected or consecutive patients into their studies over a number of months or years. Twenty-eight of the 31 studies were retrospective in nature. It was not possible to ascertain from 30 studies whether the anti-C1q assay was performed without any prior knowledge of the nephritis status of the patient samples. In many routine diagnostic studies, evaluations are frequently conducted blind to avoid bias. Only one study claimed to use the anti-C1q ELISA diagnostically. The majority of the studies (28/31) performed a renal biopsy in most of the patients to confirm LN. In 24 studies, proteinuria levels were used as a means to detect nephritis activity. Detailed analysis of raised creatinine levels was performed in 12 studies and the frequency of red blood cells/high powered field of view, was recorded in 16 studies (Table 2). The majority of studies took blood samples at the time of biopsy or disease activity assessment. The resulting isolated sera were routinely batched stored at either $-20^{\circ} \mathrm{C}$ or $-80^{\circ} \mathrm{C}$ prior to being assayed for anti-C1q autoantibodies.

The selected studies scored high for patient selection and use of appropriate clinical assessment of nephritis. However, we identified 7 studies in which the recommended cut-off values distinguishing a positive or negative result were not adhered too; for this reason the studies were graded as having 'high risk' concerns. However, an explanation for changing the cut-off values for the anti-C1q tests was provided in the analyzed studies. The main reason given for adjusting the ELISA cut-off value was to meet the needs of the individual studies based on their own non-SLE control subject analysis. In some studies the use of mean OD values \pm 1 or more SD were used, with no explanation as to why their results were not presented as ELISA units/ml. 
Citation: Eggleton P, Ukoumunne OC, Cottrell I, Khan A, Maqsood S, et al. (2014) Autoantibodies against C1q as a Diagnostic Measure of Lupus Nephritis: Systematic Review and Meta-analysis. J Clin Cell Immunol 5: 210. doi:10.4172/2155-9899.1000210

Page 8 of 14

\begin{tabular}{|c|c|c|c|c|c|c|c|}
\hline \multirow[b]{2}{*}{ STUDY } & \multirow[b]{2}{*}{$\begin{array}{c}\text { PATIENT } \\
\text { SELECTION }\end{array}$} & \multicolumn{2}{|c|}{ RISK OF BIAS } & \multirow[b]{2}{*}{$\begin{array}{l}\text { FLOW } \\
\text { AND } \\
\text { TIMING }\end{array}$} & \multicolumn{3}{|c|}{ APPLICABILITY CONCERNS } \\
\hline & & $\begin{array}{l}\text { INDEX } \\
\text { TEST }\end{array}$ & $\begin{array}{l}\text { REFERENCE } \\
\text { STANDARD }\end{array}$ & & $\begin{array}{c}\text { PATIENT } \\
\text { SELECTION }\end{array}$ & $\begin{array}{c}\text { INDEX } \\
\text { TEST }\end{array}$ & $\begin{array}{l}\text { REFERENCE } \\
\text { STANDARD }\end{array}$ \\
\hline Bernstein 1994 & ? & ? & (-); & (-); & ? & (:) & (:) \\
\hline Oelzner 2003 & (-); & ? & (-) & (:) & (-) & (;) & (-) \\
\hline Ravelli 1997 & (:) & ? & (-); & (:) & (-); & (:) & (-); \\
\hline Moura 2009 & (:) & $?$ & (2): & (:) & (:); & (:) & (:) \\
\hline Marto 2009 & (:) & $?$ & (2) & (:) & (2) & (;) & (2) \\
\hline Katsumata 2011 & (2) & $?$ & (:) & (:) & (2) & (2) & (:) \\
\hline Zhang 2011 & (-) & $?$ & (-) & (:) & (-); & (:) & (-) \\
\hline De Moura 2011 & (-); & ? & (-); & (-); & (-); & (:) & (-); \\
\hline Pradhan 2010 & (-) & $?$ & (-) & (:) & (2) & (;) & (-) \\
\hline Meyer 2009 & (:) & $?$ & (:) & (:) & (:) & (2) & (:) \\
\hline Cai 2010 & (:) & $?$ & (:) & (:) & (:) & (:) & (:) \\
\hline Trendelenburg 2006 & $?$ & $?$ & $?$ & (-) & $?$ & (2) & (-) \\
\hline Coremans 1995 & $?$ & $?$ & (-) & (:) & (2): & (;) & (-) \\
\hline Norsworthy 1999 & (-); & ? & (-); & (-): & (-); & (:) & (-); \\
\hline Loizou 2000 & (2) & $?$ & (2) & (:) & (2) & (:) & (:) \\
\hline Trendelenburg 1999 & (:) & $?$ & (-) & (:) & (:) & (-); & (:) \\
\hline Fang 2009 & (:) & $?$ & (-) & (-) & (:) & (;) & (-) \\
\hline Moroni 2001 & (2) & $?$ & (:) & (:) & (-); & (;) & (:) \\
\hline Sinico 2005 & (:) & $?$ & (2) & (2) & (-); & (:) & (-) \\
\hline Wu 2011 & (:) & $?$ & (2) & (-) & (-) & $?$ & (-) \\
\hline Tan 2009 & (:) & ? & (-); & (-); & (-); & (:) & (-); \\
\hline Mok 2010 & (:) & $?$ & $?$ & (:) & (:) & (2) & $?$ \\
\hline Braun 2007 & $?$ & ? & (-); & (-); & ? & (:) & (:) \\
\hline Siegert 1991 & (;) & $?$ & (-); & (:) & (-) & (;) & (-) \\
\hline Siegert 1993 & (-) & $?$ & (-) & (-) & (:) & (;) & (-) \\
\hline Haseley 1997 & (:) & $?$ & (:) & (:) & (:) & (:) & (:) \\
\hline Jesus 2012 & (:) & $?$ & (:) & (:) & (-) & (:) & (-) \\
\hline Pradhan 2012 & $?$ & $?$ & ()ㅜ & (2) & (2) & $?$ & (-) \\
\hline Jaekel 2006 & $?$ & $?$ & (2) & ()ㅜㅇ & (2) & (-) & ()ㅜㅇ \\
\hline Kozyro 2006 & $?$ & $?$ & $?$ & (:) & (:) & (:) & (-) \\
\hline $\begin{array}{c}\text { Smykal-Jankowiak } \\
2011\end{array}$ & $?$ & $?$ & (:) & $?$ & (:) & (2) & (-) \\
\hline & & ow Ris & 2High Risl & ? $\mathrm{Ur}_{\mathrm{s}}$ & Risk & & \\
\hline
\end{tabular}

Figure 3: QUADAS-2 quality assessment of selected studies based on inclusion rated in terms of bias and applicability. 
Citation: Eggleton P, Ukoumunne OC, Cottrell I, Khan A, Maqsood S, et al. (2014) Autoantibodies against C1q as a Diagnostic Measure of Lupus Nephritis: Systematic Review and Meta-analysis. J Clin Cell Immunol 5: 210. doi:10.4172/2155-9899.1000210

Page 9 of 14

$\begin{array}{lrrrr}\text { A } & & & & \\ \text { Study } & \text { TP } & \text { FP } & \text { FN } & \text { TN } \\ \text { Bernstein 1994 } & 4 & 3 & 26 & 27 \\ \text { Braun 2007 } & 29 & 10 & 18 & 21 \\ \text { Cai 2010 } & 58 & 11 & 15 & 29 \\ \text { Coremans 1995 } & 14 & 8 & 3 & 18 \\ \text { Fang 2009 } & 84 & 6 & 66 & 24 \\ \text { Haseley 1997 } & 61 & 18 & 78 & 83 \\ \text { Jaekel 2006 } & 24 & 10 & 13 & 53 \\ \text { Jesus 2012 } & 13 & 1 & 37 & 12 \\ \text { Katsumata 2011 } & 15 & 64 & 6 & 41 \\ \text { Loizou 2000 } & 20 & 5 & 11 & 20 \\ \text { Marto 2005 } & 50 & 24 & 27 & 50 \\ \text { Meyer 2009 } & 15 & 20 & 0 & 35 \\ \text { Mok 2010 } & 39 & 12 & 101 & 93 \\ \text { Moura 2006 } & 13 & 12 & 2 & 35 \\ \text { Moura 2009 } & 13 & 19 & 9 & 40 \\ \text { Norsworthy 1999 } & 53 & 3 & 18 & 121 \\ \text { Oelzner 2003 } & 24 & 15 & 21 & 19 \\ \text { Pradhan 2010 } & 47 & 15 & 6 & 12 \\ \text { Pradhan 2012 } & 27 & 8 & 18 & 7 \\ \text { Ravelli 1197 } & 5 & 12 & 3 & 9 \\ \text { Siegert 1991 } & 15 & 15 & 3 & 55 \\ \text { Siegert 1996 } & 15 & 14 & 6 & 33 \\ \text { Sinico 2005 } & 24 & 3 & 16 & 18 \\ \text { Tan 2009 } & 46 & 4 & 37 & 26 \\ \text { Trendelenburg 1999 } & 14 & 10 & 0 & 24 \\ \text { Trendelenbury 2006 } & 45 & 9 & 19 & 27 \\ \text { Wu 2011 } & 67 & 5 & 0 & 18 \\ \text { Zhang 2011 } & 28 & 17 & 21 & 24 \\ & & & & \end{array}$

B

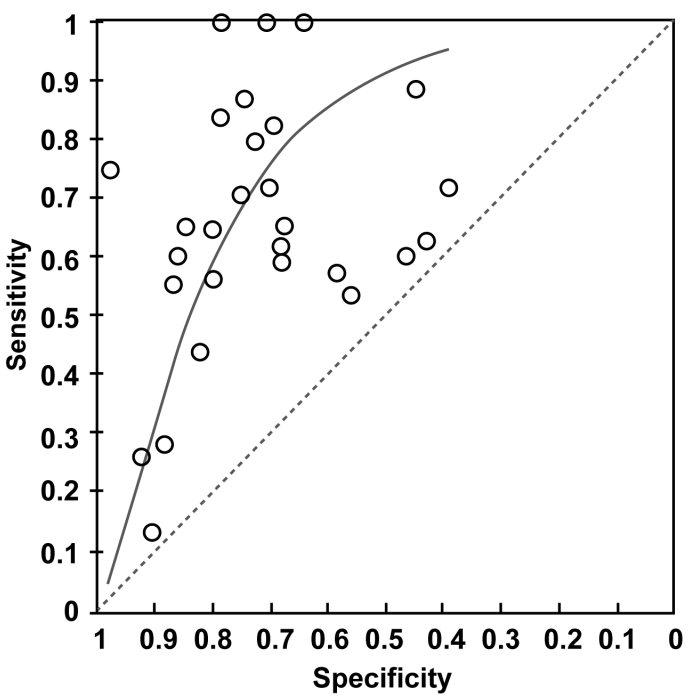

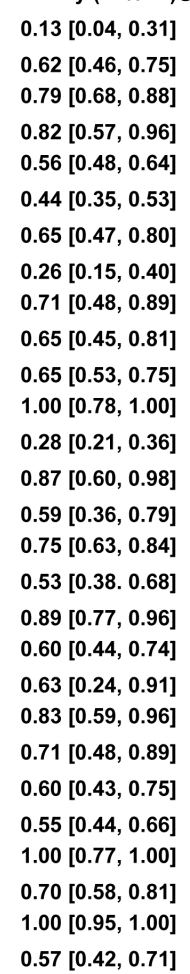

$0.57[0.42,0.71]$

\begin{tabular}{l} 
ecificity $(95 \% \mathrm{Cl})$ \\
$0.90[0.73,0.98]$ \\
$0.68[0.49,0.83]$ \\
$0.72[0.56,0.85]$ \\
$0.69[0.48,0.86]$ \\
$0.80[0.61,0.92]$ \\
$0.82[0.73,0.89]$ \\
$0.84[0.73,0.92]$ \\
$0.92[0.64,1.00]$ \\
$0.39[0.30,0.49]$ \\
$0.80[0.59,0.93]$ \\
$0.68[0.56,0.78]$ \\
$0.64[0.50,0.76]$ \\
$0.89[0.81,0.94]$ \\
$0.74[0.60,0.86]$ \\
$0.68[0.54,0.79]$ \\
$0.98[0.93,0.99]$ \\
$0.56[0.38,0.73]$ \\
$0.44[0.25,0.65]$ \\
$0.47[0.21,0.73]$ \\
$0.43[0.22,0.66]$ \\
$0.79[0.67,0.87]$ \\
$0.70[0.55,0.83]$ \\
$0.86[0.64,0.97]$ \\
$0.87[0.69,0.96]$ \\
$0.71[0.53,0.53]$ \\
$0.75[0.58,0.88]$ \\
$0.78[0.56,0.93]$ \\
$0.59[0.42,0.74]$ \\
\hline
\end{tabular}

Sensitivit
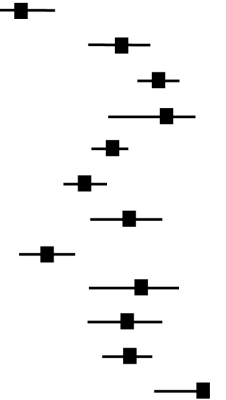

Specificity $(95 \% \mathrm{Cl})$

$\rightarrow$
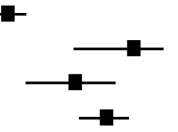

$\rightarrow-1$
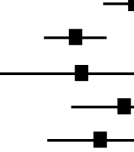

$\longrightarrow$
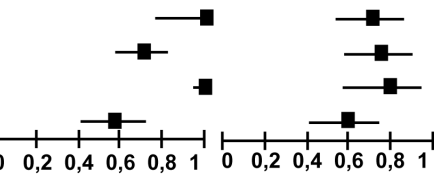

$+$

C

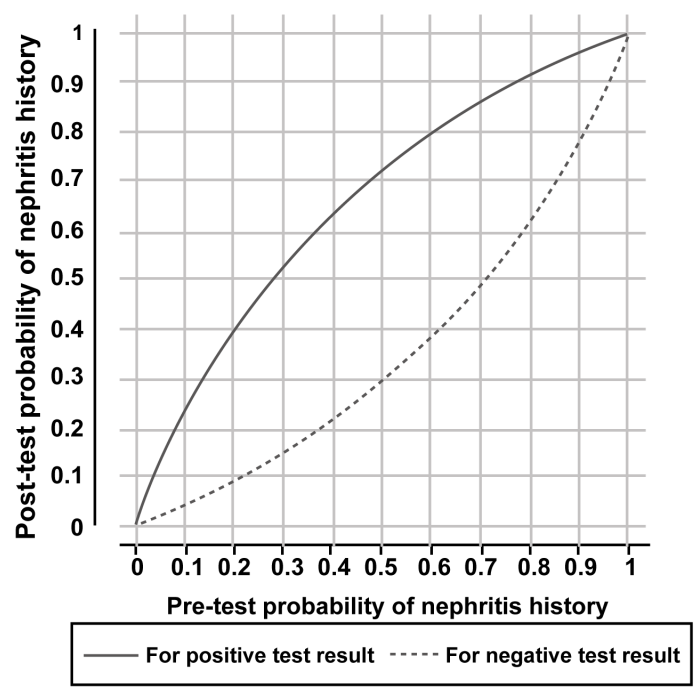

Figure 4: Comparing anti-C1q between patients with and without a history of lupus nephritis. (A) Coupled forest plot of sensitivity and specificity of anti-C1q for distinguishing between patients with and without a history of LN. The sensitivity and specificity values for each individual study are shown (squares) with 95\% confidence intervals (horizontal lines). TP - true positives; FP - false positives; FN - false negative; TN - true negatives. (B) Summary ROC plot summarizing sensitivity and specificity of anti-C1q for distinguishing between patients with and without a history of LN. Summary ROC curve based on the fitted HSROC random effects model is shown. Each circle represents an individual study. Points above the diagonal line indicate that the test has better classification than random assignment to a positive or negative test result. (C) Post-test probability of LN history versus pre-test probability. Separate curves shown based on a positive anti-C1q result and a negative anti-C1q result. 
Citation: Eggleton P, Ukoumunne OC, Cottrell I, Khan A, Maqsood S, et al. (2014) Autoantibodies against C1q as a Diagnostic Measure of Lupus Nephritis: Systematic Review and Meta-analysis. J Clin Cell Immunol 5: 210. doi:10.4172/2155-9899.1000210

Page 10 of 14

\section{Diagnostic ability of anti-C1q to distinguish between SLE patients with history of $\mathrm{LN}$ and those without a history of $\mathrm{LN}$}

Twenty eight studies provided data on the accuracy of anti-C1q to distinguish patients with a current or past history of LN from those with no history of LN. Figure 4A shows the coupled forest plot reporting the sensitivity and specificity estimates from the studies. The sensitivity and specificity points are displayed in ROC space in Figure $4 \mathrm{~B}$, with the estimated summary ROC curve from the fitted HSROC model drawn on the plot. The median of the specificity values at study level was $73.5 \%$ and the estimated corresponding sensitivity estimated by the HSROC model was $70.4 \%$ (95\% Credible Interval (CrI): $57.4 \%$ to $81.6 \%)$. The positive and negative likelihood ratios were 2.66 and 0.40 , respectively. If we apply the likelihood ratio values to a population where the underlying proportion of subjects with a history of nephritis is $55 \%$ (the median prevalence across the 28 studies) a positive test result would increase the probability of nephritis history to $76.4 \%$ and a negative test result would reduce the probability to $33.3 \%$. Figure $4 \mathrm{C}$ illustrates the post-test probabilities of a history of nephritis that corresponded to different pre-test probabilities (prevalence values), separately for those with positive and those with negative anti-C1q test results. For a test with high predictive value the curve for positive results would be close to the top of the graph and the curve for negative results close to the bottom. The figure shows that across most underlying prevalence values the anti-C1q test result does not discriminate well and generally leaves uncertainty about the presence of absence of a history of nephritis. In the few scenarios (pretest probability values above $70 \%$ ) where the post-test probability of nephritis after a positive anti-C1q result was large enough to be certain that the condition was present the post-test probability after a negative result was not sufficiently low to rule out the condition.

\section{Diagnostic ability of anti-C1q to distinguish between SLE patients with active $\mathrm{LN}$ and those with inactive $\mathrm{LN}$}

Nine studies provided data on the accuracy of anti-C1q for distinguishing patients with active nephritis from those with inactive nephritis. Figure 5A shows the coupled forest plot with sensitivity and specificity values and Figure 5B shows the study estimates in ROC space with the fitted curve from the HSROC model superimposed. The median of the specificity values of the studies was $80 \%$ and the HSROC model estimated sensitivity that corresponds to this was $75.7 \%$ (95\% CrI: $46.8 \%$ to $91.3 \%$ ). The positive and negative likelihood ratios were 3.79 and 0.30 , respectively. Applying these to a population of LN subjects where the probability of active $\mathrm{LN}$ is $56 \%$ (the median prevalence across the 9 studies), a positive test result would increase the probability to $82.8 \%$ and a negative test result would reduce the probability $27.9 \%$. Again, the respective post-test probabilities corresponding to the range of pre-test probability values are generally not sufficiently extreme to 'rule in' active LN given a positive test result nor rule it out given a negative test result, as illustrated in Figure 5C.

\section{Discussion}

There is a persisting need for lupus biomarkers that can diagnose active organ involvement during SLE disease flares. Ahearn et al. have recently highlighted this and the difficulties in identifying a specific biomarker to diagnose SLE [41,42]. Among these difficulties, Ahearn highlighted they were required to aid in a) the under- and overdiagnosis of SLE, b) identification of lupus flares, c) stratification of patients with various organ involvements and d) monitoring of therapeutic interventions. To this end over 50 potential biomarkers have been investigated for monitoring SLE [43]. Of these anti-DNA, anti-nucleosome, monocyte chemoattractant protein-1, neutrophil gelatinase-associated lipocalin, urinary tumor necrosis factor (TNF)like weak inducer of apoptosis, soluble cellular vascular adhesion molecules, C4d levels on erythrocytes, biopsy positive C4d and anti$\mathrm{C} 1 \mathrm{q}$ autoantibodies have all been investigated as renal disease biomarkers. Of these renal biomarkers, anti-C1q has persisted over three decades as a means of monitoring LN in SLE patents in research studies. Autoantibodies against $\mathrm{C} 1 \mathrm{q}$ were originally detected against the collagen-like tail region of $\mathrm{Clq}[29,44]$, but more recently it has been shown that anti-C1q antibodies are also generated against the $\mathrm{A}$, $B$ and C chains of the globular heads of C1q [45]. Our own studies have suggested oxidative modifications of common host proteins such C1q may lead to breakdown of immune tolerance [46]. C1q has abundant cysteine, methionine and phenylalanines, which are susceptible to attack by reactive oxygen species that can lead to posttranslational modifications and possible breakdown of immune tolerance by generating 'foreign-appearing' epitopes. Nitrating species such as peroxynitrite can also modify amino acids to form stable end products such as 3-nitrotyrosine that can be immunogenic [47]. This may lead to the generation of unwanted anti-C1q antibodies that can be exploited to monitor disease activity in SLE patients [48].

Many studies performed in the 1990s in northern Europe and the USA assessed anti-C1q as a biomarker for detecting LN in SLE patients. Most were enthusiastic, and whilst European centers continue to assess anti-C1q, those in the USA appear less keen in using anti-C1q to monitor LN. There has been a resurgence of interest in assessing anti-C1q as a biomarker of LN in Asia and South America, particularly in juvenile SLE patients, where renal involvement is a little more frequent than in adults [49]. In our review of 28 studies measuring anti-C1q antibodies to detect a history of LN in SLE patients and 9 studies in which anti-Clq measurement was used to distinguish between active $\mathrm{LN}$ and inactive $\mathrm{LN}$, the post-test probabilities after a positive test result were generally too low to be reasonably certain of the presence of the condition. Similarly the posttest probabilities after a negative test result were generally too high to rule out the condition with confidence. These findings apply across most of the range of hypothetical values for the prevalence of nephritis history/active nephritis and suggest the measurement of anti-C1q auto-antibodies as a 'stand-alone' biomarker is not diagnostically useful.

The sensitivity and specificity values were highly variable across the included studies (Figures 4 and 5). There are a number of possible reasons for this. Some of these factors were cited in a previous metaanalysis by Yin et al. [50], and included detection methods employed (assay errors) and ethnicity (genetic/environmental) factors. In our analysis we included studies in which commercial and noncommercial ELISA methods were utilized, A frequently used commercial assay is the Bühlmann ELISA. One recent large study of 223 SLE patients monitored anti-C1q antibodies using this and another commercial assay [51]. This individual study was not included in our current meta-analysis, but the corresponding author provided additional sub-cohort data (personal communication - $\mathrm{H}$ Julkunen) of 
Citation: Eggleton P, Ukoumunne OC, Cottrell I, Khan A, Maqsood S, et al. (2014) Autoantibodies against C1q as a Diagnostic Measure of Lupus Nephritis: Systematic Review and Meta-analysis. J Clin Cell Immunol 5: 210. doi:10.4172/2155-9899.1000210

Page 11 of 14

their study. The sensitivity, specificity, positive predictive value, and negative predictive value for distinguishing active lupus nephritis versus inactive nephritis patients $(\mathrm{n}=104)$ were $44 \%, 90 \%, 58 \%$ and $84 \%$ respectively. These values were similar to the values of other studies included in our analysis. Historically, the early studies, particularly in the 1990s had to make their own lab-based ELISAs (as they were not available commercially). Later studies, from 2003 onwards, frequently used commercially available ELISAs, but no single product has been adopted throughout the lupus-research community. For an immunoassay to be useful in routine clinical practice, clinical laboratories should adopt a single assay procedure. This is the case for measuring autoantibodies against cyclic citrullinated proteins (anti$\mathrm{CCP}$ ) as a diagnostic assay for rheumatoid arthritis in which selected commercial ELISAs are approved by the U.S. Food and Drug Administration (FDA).

\section{A}

Study

Bernstein 1994

Kozyro 2006

Marto 2005

Mok 2010

Moroni 2001

Oelzner 2003

Sinico 2005

Smykal-Jankowiak 2011

Trendelenburg 2006

$\begin{array}{rrrrr}\text { TP } & \text { FP } & \text { FN } & \text { TN } & \text { Sensitivity }(95 \% \mathrm{Cl}) \\ 3 & 1 & 12 & 14 & 0.20[0.04,0.48] \\ 6 & 1 & 1 & 4 & 0.86[0.42,1.00] \\ 32 & 18 & 11 & 16 & 0.74[0.59,0.86] \\ 23 & 16 & 20 & 81 & 0.53[0.38,0.69] \\ 20 & 3 & 3 & 35 & 0.87[0.66,0.97] \\ 14 & 10 & 5 & 16 & 0.74[0.49,0.91] \\ 24 & 0 & 3 & 13 & 0.89[0.71,0.98] \\ 26 & 4 & 8 & 10 & 0.76[0.59,0.89] \\ 36 & 9 & 2 & 17 & 0.95[0.82,0.99]\end{array}$

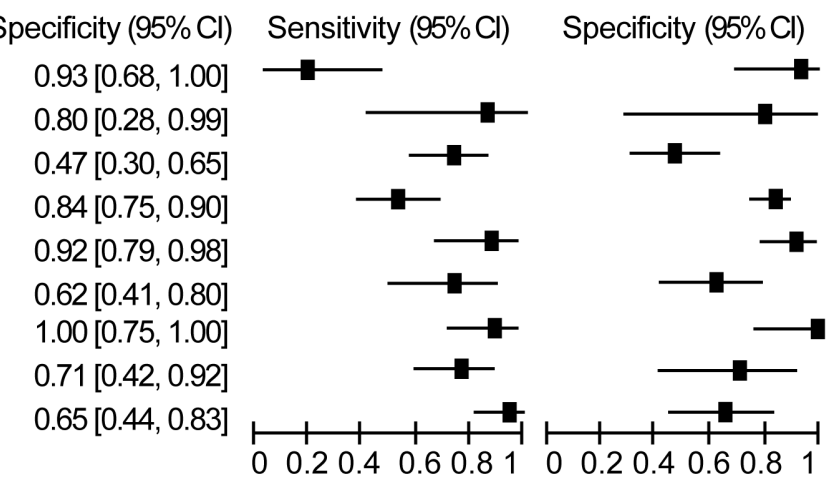

C
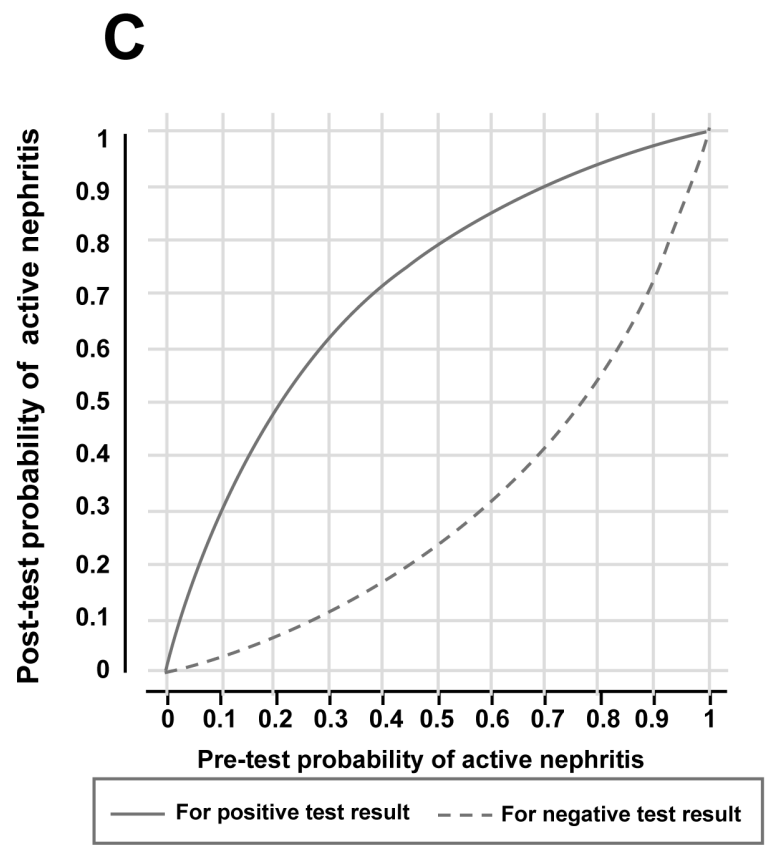

Figure 5: Comparing anti-C1q between patients with active and inactive lupus nephritis. (A) Coupled forest plot of sensitivity and specificity of anti-C1q for distinguishing between patients with active LN and those with inactive LN. The sensitivity and specificity values for each individual study are shown (squares) with 95\% confidence intervals (horizontal lines). TP - true positives; FP - false positives; FN - false negative; TN - true negatives. (B) Summary ROC plot summarizing sensitivity and specificity of anti-C1q for distinguishing between patients with active LN and those with inactive LN. Summary ROC curve based on the fitted HSROC random effects model is shown. Each circle represents an individual study. Points above the diagonal line indicate that the test has better classification than random assignment to a positive or negative test result. (C) Post-test probability of active nephritis versus pre-test probability. Separate curves shown based on a positive anti-C1q result and a negative anti-C1q result. 
Citation: Eggleton P, Ukoumunne OC, Cottrell I, Khan A, Maqsood S, et al. (2014) Autoantibodies against C1q as a Diagnostic Measure of Lupus Nephritis: Systematic Review and Meta-analysis. J Clin Cell Immunol 5: 210. doi:10.4172/2155-9899.1000210

Page 12 of 14

The inclusion of both 'lab-made' and commercial anti-C1q diagnostic ELISAs in our analysis is justified since the assay has evolved with several stringent modifications over the past 30 years. A natural function of $\mathrm{C} 1 \mathrm{q}$ is to bind non-specifically to immune complexes. Consequently, using an ELISA method employing whole purified C1q bound to a well of an ELISA plate is susceptible to binding to immune complexes present in the test sera, as well as to antibodies directed against C1q. In some of the earlier studies excluded from our analysis, this problem may have led to a higher number of false positive results. However, it was soon realized that raising the ionic strength of the test buffer to $>0.15 \mathrm{M}$ prevented the non-specific binding of immune complexes to solid-phase bound $\mathrm{Clq}$ [52], but concerns have been raised that high salt buffers can also prevent anti-C1q autoantibodies binding to $\mathrm{Clq}$ [53].Various other potential problems were raised by Siegert, including sera containing double-stranded DNA (dsDNA) that is known to bind to the collagen region of $\mathrm{C} 1 \mathrm{q}$, but increasing the salt concentration of test buffer also alleviates this problem [24]. Another concern is the specificity of the antibodies that bind to $\mathrm{Clq}$. The collagen-like region of $\mathrm{Clq}$ bears some homology to type II collagen, which is also a target for autoantibodies in many autoimmune diseases, especially SLE and rheumatoid arthritis. However, a study showed that the autoantibodies directed against type II collagen differed from those that bound to the collagen-like stalks of $\mathrm{Clq}$ [54]. We have recently developed a more sophisticated form of ELISA that uses unmodified C1q and posttranslationally modified forms of $\mathrm{C} 1 \mathrm{q}$ as a target antigen for detecting anti-C1q autoantibodies in SLE sera. This variation may prove to be a more specific and sensitive alternative to current anti-C1q ELISA's $[46,47]$.

Ten years ago Reveille indicated that the anti-DNA antibody test remained the 'gold standard' immunoassay marker for disease activity in SLE, particularly as an indicator of LN [55] with a positive likelihood ratio of 4.41. He also suggested other tests including antiClq showed promise in monitoring renal disease in SLE patients. Our study reveals a lack of homogeneity in performing the anti-C1q assay. Despite this, measuring anti-C1q autoantibodies may be a useful diagnostic test for monitoring and detecting evidence of LN in SLE patients, but not as a 'stand-alone' assay, but as part of a panel of autoantibodies as has been the recommendation for many years [56]. We would advocate that the anti-C1q immunoassay requires further refinement and development, with greater specificity and sensitivity in gauging LN before a single assay be adopted.

\section{Acknowledgements}

We would like to thank Susan Westoby for secretarial help in the production of this manuscript. We would also like to thank Buzzy Eggleton for help with analysis of the data. EP acknowledges funding support from Arthritis Research UK to EP (grant no. 19894). OU is supported by the Peninsula Collaboration for Leadership in Applied Health Research and Care (CLAHRC), a collaboration between the Universities of Exeter and Plymouth, and National Health Service South West, funded by the National Institute for Health Research, UK.

\section{Conflict of Interest}

The authors have no conflicts of interest to disclose.

\section{References}

1. Reid KB, Lowe DM, Porter RR (1972) Isolation and characterization of C1q, a subcomponent of the first component of complement, from human and rabbit sera. Biochem J 130: 749-763.

2. Augener W, Grey HM, Cooper NR, Müller-Eberhard HJ (1971) The reaction of monomeric and aggregated immunoglobulins with $\mathrm{C} 1$. Immunochemistry 8: 1011-1020.

3. Eggleton P, Reid KB, Tenner AJ (1998) C1q--how many functions? How many receptors? Trends Cell Biol 8: 428-431.

4. Lewis EJ, Busch GJ, Schur PH (1970) Gamma G globulin subgroup composition of the glomerular deposits in human renal diseases. J Clin Invest 49: 1103-1113.

5. Gasque P (2004) Complement: a unique innate immune sensor for danger signals. Mol Immunol 41: 1089-1098.

6. Botto M, Walport MJ (2002) C1q, autoimmunity and apoptosis. Immunobiology 205: 395-406.

7. Agnello V, Koffler D, Eisenberg JW, Winchester RJ, Kundel HG (1971) Clg precipitins in the sera of patients with systemic lupus erythematosus and other hypocomplementemic states: characterization of high and low molecular weight types. J Exp Med 134: 228s-241s.

8. Golan MD, Burger R, Loos M (1982) Conformational changes in $\mathrm{Clq}$ after binding to immune complexes: detection of neoantigens with monoclonal antibodies. J Immunol 129: 445-447.

9. Uwatoko S, Aotsuka S, Okawa M, Egusa Y, Yokohari R, et al. (1984) Characterization of Clq-binding IgG complexes in systemic lupus erythematosus. Clin Immunol Immunopathol 30: 104-116.

10. Eggleton P, Szestakowska D, Winyard PG, Viner N, Nissim A (2006) Generation of neo-antigenic epitopes recognised by autoimmune sera after the post-translational modification of human C1q by free radicals. Rheumatology (Oxford) 45: I103.

11. Eggleton P, Ryan B, Brown S, Johnson S, Viner N, et al. (2011) PostTranslational Modifications of C1q Lead to Antigenicity and Breakdown of Immune Tolerance in Systemic Lupus Erythematosus. Clin Exp Rheumatol 29: 176.

12. Eggleton P, Haigh R, Winyard PG (2008) Consequence of neoantigenicity of the 'altered self. Rheumatology (Oxford) 47: 567-571.

13. Trinder PK, Maeurer MJ, Stoerkel SS, Loos M (1997) Altered (oxidized) C1q induces a rheumatoid arthritis-like destructive and chronic inflammation in joint structures in arthritis-susceptible rats. Clin Immunol Immunopathol 82: 149-156.

14. Donnelly S, Roake W, Brown S, Young P, Naik H, et al. (2006) Impaired recognition of apoptotic neutrophils by the C1q/calreticulin and CD91 pathway in systemic lupus erythematosus. Arthritis Rheum 54: 1543-1556.

15. Kovacs H, Campbell ID, Strong P, Johnson S, Ward FJ, et al. (1998) Evidence that $\mathrm{Clq}$ binds specifically to $\mathrm{CH} 2$-like immunoglobulin gamma motifs present in the autoantigen calreticulin and interferes with complement activation. Biochemistry 37: 17865-17874.

16. Yu C, Gershwin ME, Chang C (2014) Diagnostic criteria for systemic lupus erythematosus: A critical review. J Autoimmun 48-49C: 10-13.

17. Seshan SV, Jennette JC (2009) Renal disease in systemic lupus erythematosus with emphasis on classification of lupus glomerulonephritis: advances and implications. Arch Pathol Lab Med 133: 233-248.

18. Sidiropoulos PI, Kritikos HD, Boumpas DT (2005) Lupus nephritis flares. Lupus 14: 49-52.

19. Ortega LM, Schultz DR, Lenz O, Pardo V, Contreras GN (2010) Review: Lupus nephritis: pathologic features, epidemiology and a guide to therapeutic decisions. Lupus 19: 557-574.

20. Bertsias GK, Salmon JE, Boumpas DT (2010) Therapeutic opportunities in systemic lupus erythematosus: state of the art and prospects for the new decade. Ann Rheum Dis 69: 1603-1611. 
Citation: Eggleton P, Ukoumunne OC, Cottrell I, Khan A, Maqsood S, et al. (2014) Autoantibodies against C1q as a Diagnostic Measure of Lupus Nephritis: Systematic Review and Meta-analysis. J Clin Cell Immunol 5: 210. doi:10.4172/2155-9899.1000210

Page 13 of 14

21. Bertsias G, Boumpas DT (2008) Update on the management of lupus nephritis: let the treatment fit the patient. Nat Clin Pract Rheumatol 4: 464-472.

22. Isenberg DA (1997) Autoantibodies: markers of disease or pathogenic? Ann N Y Acad Sci 823: 256-262.

23. Giles I, Isenberg D (2007) Antinuclear antibodies: An overview. In: Wallace DJ, Hahn B, Dubois EL (eds), Dubois' lupus erythematosus. (7thedn) Lippincott Williams \& Wilkin, Philadelphia, London, pp: 432-441.

24. Siegert CE, Kazatchkine MD, Sjöholm A, Würzner R, Loos M, et al. (1999) Autoantibodies against Clq: view on clinical relevance and pathogenic role. Clin Exp Immunol 116: 4-8.

25. Davies KA, Norsworthy PJ, Athanassiou P, Walport MJ (1997) Anti-C1q antibodies activate complement and may be pathogenic in SLE. Arthritis Rheum 40: 1661.

26. Bernstein KA, Kahl LE, Balow JE, Lefkowith JB (1994) Serologic markers of lupus nephritis in patients: use of a tissue-based ELISA and evidence for immunopathogenic heterogeneity. Clin Exp Immunol 98: 60-65.

27. Coremans IE, Spronk PE, Bootsma H, Daha MR, van der Voort EA, et al. (1995) Changes in antibodies to C1q predict renal relapses in systemic lupus erythematosus. Am J Kidney Dis 26: 595-601.

28. Haseley LA, Wisnieski JJ, Denburg MR, Michael-Grossman AR, Ginzler EM, et al. (1997) Antibodies to C1q in systemic lupus erythematosus: characteristics and relation to Fc gamma RIIA alleles. Kidney Int 52: 1375-1380.

29. Norsworthy P, Theodoridis E, Botto M, Athanassiou P, Beynon H, et al. (1999) Overrepresentation of the Fcgamma receptor type IIA R131/R131 genotype in caucasoid systemic lupus erythematosus patients with autoantibodies to $\mathrm{Clq}$ and glomerulonephritis. Arthritis Rheum 42: 1828-1832.

30. Siegert C, Daha M, Westedt ML, van der Voort E, Breedveld F (1991) IgG autoantibodies against $\mathrm{Clq}$ are correlated with nephritis, hypocomplementemia, and dsDNA antibodies in systemic lupus erythematosus. J Rheumatol 18: 230-234.

31. Siegert CE, Daha MR, Tseng CM, Coremans IE, van Es LA, et al. (1993) Predictive value of IgG autoantibodies against $\mathrm{Clq}$ for nephritis in systemic lupus erythematosus. Ann Rheum Dis 52: 851-856.

32. Trendelenburg M, Courvoisier S, Späth PJ, Moll S, Mihatsch M, et al (1999) Hypocomplementemic urticarial vasculitis or systemic lupus erythematosus? Am J Kidney Dis 34: 745-751.

33. Katsumata Y, Miyake K, Kawaguchi Y, Okamoto Y, Kawamoto M, et al. (2011) Anti-Clq antibodies are associated with systemic lupus erythematosus global activity but not specifically with nephritis: a controlled study of 126 consecutive patients. Arthritis Rheum 63: 2436-2444

34. Moroni G, Radice A, Giammarresi G, Quaglini S, Gallelli B, et al. (2009) Are laboratory tests useful for monitoring the activity of lupus nephritis? A 6-year prospective study in a cohort of 228 patients with lupus nephritis. Ann Rheum Dis 68: 234-237.

35. Horváth L, Czirják L, Fekete B, Jakab L, Pozsonyi T, et al. (2001) High levels of antibodies against $\mathrm{Clq}$ are associated with disease activity and nephritis but not with other organ manifestations in SLE patients. Clin Exp Rheumatol 19: 667-672.

36. Whiting PF, Rutjes AW, Westwood ME, Mallett S, Deeks JJ, et al. (2011) QUADAS-2: a revised tool for the quality assessment of diagnostic accuracy studies. Ann Intern Med 155: 529-536.

37. Rutter CM, Gatsonis CA (2001) A hierarchical regression approach to meta-analysis of diagnostic test accuracy evaluations. Stat Med 20: 2865-2884.

38. Review Manager. RevMan 5.2 User Guide. In: The Nordic Cochrane Center TCC, ed. Copenhagen; 2012.

39. Hochberg MC (1997) Updating the American College of Rheumatology revised criteria for the classification of systemic lupus erythematosus. Arthritis Rheum 40: 1725.
40. Tan EM, Cohen AS, Fries JF, Masi AT, McShane DJ, et al. (1982) The 1982 revised criteria for the classification of systemic lupus erythematosus. Arthritis Rheum 25: 1271-1277.

41. Liu CC, Kao AH, Manzi S, Ahearn JM (2013) Biomarkers in systemic lupus erythematosus: challenges and prospects for the future. Ther Adv Musculoskelet Dis 5: 210-233.

42. Ahearn JM, Manzi S, Liu CC (2014) The lupus biomarker odyssey: one experience. Methods Mol Biol 1134: 17-35.

43. Ahearn JM, Liu CC, Kao AH, Manzi S (2012) Biomarkers for systemic lupus erythematosus. Transl Res 159: 326-342.

44. Wisnieski JJ, Jones SM (1992) Comparison of autoantibodies to the collagen-like region of $\mathrm{Clq}$ in hypocomplementemic urticarial vasculitis syndrome and systemic lupus erythematosus. J Immunol 148: 1396-1403.

45. Tan Y, Zhou W, Yu F, Fang Q, Yang HZ, et al. (2009) Detection of antiC1q antibodies and anti-C1q globular head domain antibodies in sera from Chinese patients with lupus nephritis. Mol Immunol 46: 2178-2182.

46. Eggleton P, Nissim A, Ryan BJ, Whiteman M, Winyard PG (2013) Detection and isolation of human serum autoantibodies that recognize oxidatively modified autoantigens. Free Radic Biol Med 57: 79-91.

47. Ryan BJ, Eggleton P (2014) Detection and characterization of autoantibodies against modified self-proteins in SLE sera after exposure to reactive oxygen and nitrogen species. Methods Mol Biol 1134: 163-171.

48. Ryan B, Winyard P, Viner N, Haigh R, Haas M, et al. (2009) Oxidative modifications to $\mathrm{Clq}$ increase the sensitivity of an anti-C1q ELISA in the diagnosis of systemic lupus erythematosus. Rheumatology (Oxford) 48: i2.

49. Hoffman IE, Lauwerys BR, De Keyser F, Huizinga TW, Isenberg D, et al (2009) Juvenile-onset systemic lupus erythematosus: different clinical and serological pattern than adult-onset systemic lupus erythematosus. Ann Rheum Dis 68: 412-415.

50. Yin $Y$, Wu X, Shan G, Zhang X (2012) Diagnostic value of serum antiC1q antibodies in patients with lupus nephritis: a meta-analysis. Lupus 21: 1088-1097.

51. Julkunen H, Ekblom-Kullberg S, Miettinen A (2012) Nonrenal and renal activity of systemic lupus erythematosus: a comparison of two anti-Cla and five anti-dsDNA assays and complement C3 and C4. Rheumatol Int 32: $2445-2451$

52. Siegert CE, Daha MR, van der Voort EA, Breedveld FC (1990) IgG and IgA antibodies to the collagen-like region of $\mathrm{Clq}$ in rheumatoid vasculitis. Arthritis Rheum 33: 1646-1654.

53. Kohro-Kawata J, Wener MH, Mannik M (2002) The effect of high salt concentration on detection of serum immune complexes and autoantibodies to $\mathrm{C} 1 \mathrm{q}$ in patients with systemic lupus erythematosus. J Rheumatol 29: 84-89.

54. Sjoholm AG, Martensson U, Sturfelt G (1997) Serial analysis of autoantibody responses to the collagen-like region of Clq, collagen type II, and double stranded DNA in patients with systemic lupus erythematosus. J Rheumatol 24: 871-878.

55. Reveille JD (2004) Predictive value of autoantibodies for activity of systemic lupus erythematosus. Lupus 13: 290-297.

56. Isenberg DA, Dudeney C, Williams W, Addison I, Charles S, et al. (1987) Measurement of anti-DNA antibodies: a reappraisal using five different methods. Ann Rheum Dis 46: 448-456.

57. Ravelli A, Wisnieski JJ, Ramenghi B, Ballardini G, Zonta L, et al. (1997) IgG autoantibodies to complement $\mathrm{Clq}$ in pediatric-onset systemic lupus erythematosus. Clin Exp Rheumatol 15: 215-219.

58. Trendelenburg M, Marfurt J, Gerber I, Tyndall A, Schifferli JA (1999) Lack of occurrence of severe lupus nephritis among anti-Clq autoantibody-negative patients. Arthritis Rheum 42: 187-188.

59. Loizou S, Samarkos M, Norsworthy PJ, Cazabon JK, Walport MJ, et al. (2000) Significance of anticardiolipin and anti-beta(2)-glycoprotein I antibodies in lupus nephritis. Rheumatology (Oxford) 39: 962-968. 
Citation: Eggleton P, Ukoumunne OC, Cottrell I, Khan A, Maqsood S, et al. (2014) Autoantibodies against C1q as a Diagnostic Measure of Lupus Nephritis: Systematic Review and Meta-analysis. J Clin Cell Immunol 5: 210. doi:10.4172/2155-9899.1000210

Page 14 of 14

60. Moroni G, Trendelenburg M, Del Papa N, Quaglini S, Raschi E, et al. (2001) Anti-C1q antibodies may help in diagnosing a renal flare in lupus nephritis. Am J Kidney Dis 37: 490-498.

61. Oelzner P, Deliyska B, Fünfstück R, Hein G, Herrmann D, et al. (2003) Anti-C1q antibodies and antiendothelial cell antibodies in systemic lupus erythematosus - relationship with disease activity and renal involvement. Clin Rheumatol 22: 271-278.

62. Marto N, Bertolaccini ML, Calabuig E, Hughes GR, Khamashta MA (2005) Anti-C1q antibodies in nephritis: correlation between titres and renal disease activity and positive predictive value in systemic lupus erythematosus. Ann Rheum Dis 64: 444-448.

63. Sinico RA, Radice A, Ikehata M, Giammarresi G, Corace C, et al. (2005) Anti-C1q autoantibodies in lupus nephritis: prevalence and clinical significance. Ann N Y Acad Sci 1050: 193-200.

64. Jaekell HP, Trabandt A, Grobe N, Werle E (2006) Anti-dsDNA antibody subtypes and anti-C1q antibodies: toward a more reliable diagnosis and monitoring of systemic lupus erythematosus and lupus nephritis. Lupus 15: 335-345.

65. Kozyro I, Perahud I, Sadallah S, Sukalo A, Titov L, et al. (2006) Clinica value of autoantibodies against $\mathrm{C1q}$ in children with glomerulonephritis. Pediatrics 117: 1663-1668.

66. Trendelenburg M, Lopez-Trascasa M, Potlukova E, Moll S, Regenass S, et al. (2006) High prevalence of anti-C1q antibodies in biopsy-proven active lupus nephritis. Nephrol Dial Transplant 21: 3115-3121.

67. Braun A, Sis J, Max R, Mueller K, Fiehn C, et al. (2007) Anti-chromatin and anti-C1q antibodies in systemic lupus erythematosus compared to other systemic autoimmune diseases. Scand J Rheumatol 36: 291-298.

68. Meyer OC, Nicaise-Roland P, Cadoudal N, Grootenboer-Mignot S Palazzo E, et al. (2009) Anti-C1q antibodies antedate patent active glomerulonephritis in patients with systemic lupus erythematosus. Arthritis Res Ther 11: R87.

69. Smykal-Jankowiak K, Niemir ZI, Polcyn-Adamczak M (2011) Do circulating antibodies against $\mathrm{C} 1 \mathrm{q}$ reflect the activity of lupus nephritis? Pol Arch Med Wewn 121: 287-295.

70. Fang QY, Yu F, Tan Y, Xu LX, Wu LH, et al. (2009) Anti-C1q antibodies and IgG subclass distribution in sera from Chinese patients with lupus nephritis. Nephrol Dial Transplant 24: 172-178.
71. Cai X, Yang X, Lian F, Lin X, Liang M, et al. (2010) Correlation between serum anti-C1q antibody levels and renal pathological characteristics and prognostic significance of anti-C1q antibody in lupus nephritis. J Rheumatol 37: 759-765.

72. Mok CC, Ho LY, Leung HW, Wong LG (2010) Performance of anti-C1q, antinucleosome, and anti-dsDNA antibodies for detecting concurrent disease activity of systemic lupus erythematosus. Transl Res 156: 320-325.

73. Pradhan V, Patwardhan M, Nadkarni A, Ghosh K (2010) Fc $\gamma$ RIIA Genotypes and Its Association with Anti-C1q Autoantibodies in Lupus Nephritis (LN) Patients from Western India. Autoimmune Dis 2010: 470695.

74. Wu FQ, Zhao Q, Cui XD, Zhang W (2011) C1q and anti-C1q antibody levels are correlated with disease severity in Chinese pediatric systemic lupus erythematosus. Rheumatol Int 31: 501-505.

75. Zhang CQ, Ren L, Gao F, Mu FY, You YQ, et al. (2011) Anti-C1q antibodies are associated with systemic lupus erythematosus disease activity and lupus nephritis in northeast of China. Clin Rheumatol 30: 967-973.

76. Pradhan V, Rajadhyaksha A, Mahant G, Surve P, Patwardhan M, et al. (2012) Anti-C1q antibodies and their association with complement components in Indian systemic lupus erythematosus patients. Indian J Nephrol 22: 353-357.

77. Moura CG, Lima I, Barbosa L, Athanazio D, Reis E, et al. (2009) AntiC1q antibodies: association with nephritis and disease activity in systemic lupus erythematosus. J Clin Lab Anal 23: 19-23.

78. Moura CG, Mangueira CL, Cruz LA, Cruz CM (2011) Negative anti-C1q antibody titers may influence therapeutic decisions and reduce the number of renal biopsies in systemic lupus erythematosus. Nephron Clin Pract 118: c355-360.

79. Jesus AA, Campos LM, Liphaus BL, Carneiro-Sampaio M, Mangueira CL, et al. (2012) Anti-C1q, anti-chromatin/nucleosome, and anti-dsDNA antibodies in juvenile systemic lupus erythematosus patients. Rev Bras Reumatol 52: 976-981. 